\title{
Effects of Perception of Health on Hemodialysis Dependent Individuals' Nonadherence to Diet and Fluid Restriction
}

\author{
Safiye Yanmış ${ }^{1 *}$ and Seher Ergüney ${ }^{2}$ \\ ${ }^{1}$ Erzincan Binali Yıldırım University \\ Faculty of Health Science, Department of Internal Medicine Nursing, Erzincan, Turkey \\ Email: safiyeyanmis61 [AT] gmail.com \\ ${ }^{2}$ Ataturk University, Faculty of Nursing \\ Department of Internal Medicine Nursing, Erzurum, Turkey \\ Email: seher [AT] atauni.edu.tr \\ ${ }^{*}$ Corresponding author's email: safiyeyanmis61 [AT] gmail.com
}

\begin{abstract}
Purpose: The present study was conducted to determine the effects of health perception on hemodialysis-dependent individuals' noncompliance to diet and fluid restriction. Material and method: The study was designed as a descriptive, cross -sectional, and correlational study. Findings: In the study, it was determined that the perception of health is related to a noncompliance to diet and fluid restriction and that their noncompliance to diet and fluid restriction levels decreased as their levels perception of health increased. Conclusion: Determining hemodialysis-dependent individuals' perception of health and providing them with professional support will contribute to reducing noncompliance to diet and fluid restriction.
\end{abstract}

Keywords- Diet, hemodialysis, perception of health, fluid restriction, nonadherence.

\section{INTRODUCTION}

Chronic kidney disease (CKD) is a decline in glomerular filtration rate and the development of kidney damage, whatever the underlying etiology is. Progressive and irreversible decline in glomerular filtration rate leads to chronic renal failure [1,2]. CKD is a common health problem in our country and all over the world; and it is increasing in prevalence gradually [3,4]. It is estimated that 850 million people have kidney disease for various reasons worldwide. CKD causes at least 2.4 million deaths per year and it is currently the sixth leading cause of death with increasing prevalence. According to the Turkish Society of Nephrology's Registry 2018 end-of-year report, there were 81.055 individuals in Turkey receiving hemodialysis (HD), peritoneal dialysis (PD) and renal transplantation (RT) therapies [3].

In recent years, perception of health has been a common method used to determine health status of people. Perception of poor health is reported to be a determinant of mortality in the elderly as well as in middle-aged individuals. The prevalence of chronic diseases increases as the age increases. Therefore, the investigation of perception of health and mortality necessitated the investigation of the existence of chronic diseases. However, even if chronic diseases are excluded, the association between perception of poor health and mortality is important [5,6]. Health perception (or perceived health status) is described subjective rating by the affected individual of his or her health status [7]. Perception of health, a subjective concept, is of importance for hemodialysis-dependent individuals as for all other individuals with chronic diseases due to lifestyle changes they have to make because HD therapy leads to problems such as fatigue and weakness in the short term, and in the long term, to the deterioration of physical functioning and perception of general health due to physical problems and to the difficulties in the fulfillment of roles and responsibilities due to physical and emotional problems $[8,9]$.

Perception of health and its management provide a perspective for an individual regarding his/her health status or behaviors that he/she displays to be healthy. Individuals' perceiving their health status as bad may cause them to display unhealthy lifestyle behaviors. Therefore, individuals' perception of health should be determined well by health professionals. If an individual is unable to perceive the level of his/her health, he/she will not make an effort necessary to be healthy and will not accept help from health professionals in this regard [5,10-13].

Hemodialysis (HD), which causes an individual to make lifestyle changes, also leads to such concepts as compliance or noncompliance to treatment, another subjective health data. Having to make changes in eating habits and preferences are the leading factors causing noncompliance to treatment in individuals. Among the other factors are the restricted 
fluid, protein and potassium $\left(\mathrm{K}^{+}\right)$intake, decrease in physical activities, work force and economic losses due to the treatment program, and having to comply with treatment and changes in the lifestyle [14,15]. It is thought that not only each of the concepts of perception of health and compliance to treatment alone but also the interaction between these concepts can affect sufferers.

Studies describe how the role traditions and culture play in shaping dietary patterns and demonstrate why treating dietary practices as centered on food is less useful than looking at cultural and social systems in which food plays a central role [16,17]. In addition, Rosner [18] and Murali et al. [19] points out that individuals' cultural beliefs, support they receive from the family and other people around them and their perception of health play an important role in their compliance to the treatment of chronic diseases. As indicated in several studies, addressing compliance to treatment in HD-dependent individuals may improve not only the efficacy and quality of treatment but also sufferers' well-being and perception of health $[15,18]$. Therefore, HD nurses should carefully determine patients' compliance to treatment and lifestyle changes and take necessary steps individually or as a team [19,20]. If HD nurses know how a patient perceives and controls his/her health behaviors, they can improve the patient's compliance to HD treatment and lifestyle changes by encouraging his/her right behaviors and improving the wrong ones.

\section{MATERIAL AND METHOD}

\subsection{Purpose and Type of the Study}

This descriptive study was aimed at determining the effects of perception of health on hemodialysis-dependent individuals' noncompliance to diet and fluid restriction.

\subsection{Date and Place of the Study}

The study was conducted at the dialysis unit of a University Medical Faculty Hospital between November 1, 2013 and December 30, 2013.

\subsection{The study population and sample}

The study population comprised adult patients between 18-80 years who were treated either continuously or temporarily at the dialysis unit of a University Medical Faculty Hospital between November 2013 and December 2013. We took $\alpha=0.05 ; \beta=0.20 ;(1-\beta)=0.80$; Effect size $=0.56$ (According to literature). Accordingly, it was decided to recruit 100 people and the power of the test was found to be $\mathrm{P}=80.53$. The study sample consisted of 100 patients. Of them, 62 were registered in the dialysis center and treated continuously in this center, and 38 were not enrolled in the dialysis unit and had treatment temporarily between November 1, 2013 and December 30, 2013.

\subsubsection{Personal Information Form}

The form developed by the researcher in the light of the literature questions the participants' socio-demographic characteristics, healthy lifestyle behaviors and disease-related characteristics [8,10,11,14,19,21,22].

\subsubsection{Perception of Health Scale (PHS)}

The scale developed by Diamond et al. [23]. to assess the perception of health includes 4 sub-dimensions (control center, self-awareness, certainty and importance of health) and 15 items. The scale is a five-point Likert-type scale. The validity and reliability study of the Turkish version of the scale was carried out by Kadioglu and Yildiz. While the items $1,5,9,10,11$ and 14 of the scale are positive statements, the items 2, 3, 4, 6, 7, 8, 12, 13 and 15 are negative statements. The minimum and maximum possible scores to be obtained from the scale are 15 and 75 respectively. The participants were asked to respond the data collection tools administered to them and then to return them to the researcher. The Cronbach's Alpha values in Kadioglu and Yildiz' s study were 0.90 for the control center subscale, 0.91 for the selfawareness subscale, 0.91 for the certainty subscale and 0.82 for the importance of health subscale [11].

\subsubsection{Dialysis Diet and Fluid Noncompliance Questionnaire (DDFQ)}

The DDFQ was originally developed by Vlaminck et al. [22]. The DDFQ is a self-report tool consisting of four subscales that assess noncompliance to dietary and fluid intake restriction in HD patients. The subscales 1 and 2 are on noncompliance to diet restriction, whereas the items 3 and 4 are on noncompliance to fluid intake restriction in terms of frequency and severity. The frequency of noncompliance to diet restriction (FNDR) and the frequency of noncompliance to fluid restriction (FNFR) are assessed by questioning the number of days when the participants have displayed noncompliance behaviors within the last 14 days. The severity of noncompliance to diet restriction (SNDR) and the severity of noncompliance to fluid restriction (SNFR) was rated on a four-point Likert-type scale ranging from 0 to 4 (No noncompliance $=0$, Mild noncompliance $=1$, Moderate noncompliance $=2$, Severe noncompliance $=3$, Very severe noncompliance $=4)$. The DDFQ was adapted into Turkish by Kara and was considered as a valid and reliable measurement tool [21]. The Cronbach's Alpha values in Kara's study was 0.70 for the DDFQ [21] and the Cronbach's 
Alpha values in our study was 0.81 for the DDFQ.

\subsection{Data Collection}

The data were collected between November 2013 and December 2013. To collect the research data, the personal information form, PHS and DDFQ were used. The data were collected by the researcher while the patients received dialysis treatment. The face-to-face interview technique was used to collect the data. Before the data were collected, the participants were informed about the study and their verbal and written consent was obtained. It took each participant about 15 to 30 minutes to respond to the tools. The researcher read out the survey questions to the individuals and recorded their responses.

\subsection{Analysis of the Study Data}

The data were analyzed using the Statistical Package for Social Science (SPSS) 20.0. In the analysis of the participants' socio-demographic characteristics and the scores they obtained from the subscales of the PHS and DDFQ, descriptive statistics were used. Because the socio-demographic characteristics and the scores obtained from the subscales of the PHS and DDFQ were not distributed normally, the Mann Whitney U test was used for the comparison when there were two variables, and the Kruskal Wallis test was used for the comparison when there were more than two variables. In order to determine the relationship between the subscales of the PHS and DDFQ, the Spearman's Rank Correlation was used. The confidence interval for the results was at $95 \%$. P values between $<0.01$ and $\mathrm{p}<0.05$ were considered significant.

\subsection{Ethical Considerations}

The study was performed according to the Helsinki Declaration, and Ethics Committee of a University's Faculty of Health Sciences (Ethical approval date: October 10, 2013; Ethical approval Number: 45361945-03 / 13222) approved this study The purpose and method of the study were explained to the participants by the researcher, and their verbal and written informed consent was obtained.

\section{FINDINGS}

The mean age of the participants was $42.98 \pm 16.24$. Of them, $53 \%$ were in the 51 and over age group. $15 \%$ were in the age group of $35-42$ years, $52 \%$ were female, $72 \%$ were married, $38 \%$ had the bachelor's degree, $54 \%$ perceived their health status as moderate, $65 \%$ had another chronic disease, $35.3 \%$ had hypertension, $74 \%$ were nonsmokers, $79 \%$ regularly took their medication, and 45\% consumed 1.6-3 liters of fluid daily (Table 1).

Table 1. Distribution of the Participants in Terms of Their Socio-demographic Characteristics $(\mathrm{N}=100)$

\begin{tabular}{|c|c|c|c|c|}
\hline \multicolumn{3}{|l|}{ Characteristic } & \multirow{2}{*}{$\frac{\mathbf{n}}{12}$} & \multirow{2}{*}{$\begin{array}{c}\% \\
12.0\end{array}$} \\
\hline Age & 19-26 years & & & \\
\hline & $27-34$ years & $\mathrm{X} \pm \mathrm{SD}=42.98 \pm 16.24$ & 10 & 10.0 \\
\hline & $35-42$ years & & 15 & 15.0 \\
\hline & $43-50$ years & & 10 & 10.0 \\
\hline & $\geq 51$ years & & 53 & 53.0 \\
\hline \multirow[t]{2}{*}{ Gender } & Female & & 52 & 52.0 \\
\hline & Male & & 48 & 48.0 \\
\hline \multirow[t]{2}{*}{ Marital status } & Married & & 72 & 72.0 \\
\hline & Single & & 28 & 28.0 \\
\hline \multirow[t]{4}{*}{ Education Status } & Literate & & 9 & 9.0 \\
\hline & Primary school & & 20 & 20.0 \\
\hline & High school & & 33 & 33.0 \\
\hline & Undergraduate & & 38 & 38.0 \\
\hline Perception of General Health & Poor & & 20 & 20.0 \\
\hline \multirow[t]{3}{*}{ Status } & Moderate & & 54 & 54.0 \\
\hline & Good & & 17 & 17.0 \\
\hline & Very good & & 9 & 9.0 \\
\hline Presence of Comorbid & No & & 35 & 35.0 \\
\hline Disease and the Type of the & Yes $(n=65)$ & Hypertension & 22 & 34.0 \\
\hline \multirow{3}{*}{ Disease } & & Diabetes mellitus & 23 & 35.3 \\
\hline & & Heart failure & 12 & 18.4 \\
\hline & & Respiratory disease & 8 & 12.3 \\
\hline Duration of Undergoing & $<1$ year & & 14 & 14.0 \\
\hline \multirow[t]{3}{*}{ Dialysis } & $1-5$ years & $\mathrm{X} \pm \mathrm{SD}=80.57 \pm 61.12$ & 37 & 37.0 \\
\hline & $6-10$ years & month & 22 & 22.0 \\
\hline & $11-19$ years & & 27 & 27.0 \\
\hline
\end{tabular}




\begin{tabular}{|c|c|c|c|c|}
\hline \multirow{4}{*}{$\begin{array}{l}\text { Amount of Daily Fluid } \\
\text { Consumption (Liter per Day) }\end{array}$} & & 15 & 15.0 \\
\hline & \multicolumn{2}{|l|}{$1-1.51 t$} & 35 & 35.0 \\
\hline & $1.6-31 \mathrm{t}$ & & 45 & 45.0 \\
\hline & \multicolumn{2}{|l|}{$\geq 31 t$} & 5 & 5.0 \\
\hline \multirow[t]{2}{*}{ Regular Medication Use } & \multicolumn{2}{|l|}{ Yes } & 79 & 79.0 \\
\hline & \multicolumn{2}{|l|}{ No } & 21 & 21.0 \\
\hline \multirow{4}{*}{$\begin{array}{l}\text { Smoking Status and the } \\
\text { Number of Cigarettes } \\
\text { Smoked per Day }\end{array}$} & \multirow{4}{*}{$\begin{array}{l}\text { Nonsmoker } \\
\text { Smoker }(n=26)\end{array}$} & & 74 & 74.0 \\
\hline & & $1-5$ & 6 & 23.1 \\
\hline & & $\begin{array}{l}6-10 \\
>11\end{array}$ & 12 & 46.2 \\
\hline & & $\geq 11$ & 8 & 30.7 \\
\hline
\end{tabular}

X: Mean, SD: Standart Deviation

The mean scores the participants obtained from the overall PHS were $44.07 \pm 8.42$ (Table 2).

Table 2. Distribution of the Mean Scores Obtained from the Overall PHS

\begin{tabular}{l|c|c|c|c|c|}
\hline & X \pm SD & Median & Max & Max \\
\hline Overall PHS & $44.07 \pm 8.42$ & 47.0 & 22.0 & 72.0 \\
\hline
\end{tabular}

PHS: Perception of Health Scale, X: Mean, SD: Standart Deviation, Min: Minimum, Max: Maximum

The analysis of the participants' compliance to diet restriction revealed that $31 \%$ complied with their diet, $21 \%$ displayed mild noncompliance, $22 \%$ displayed moderate noncompliance, $7 \%$ displayed severe noncompliance and $19 \%$ displayed very severe noncompliance. The analysis of their noncompliance to fluid restriction demonstrated that of them, $30 \%$ complied with the fluid restriction, $31 \%$ displayed mild noncompliance, $16 \%$ displayed moderate noncompliance, $6 \%$ displayed severe noncompliance and $17 \%$ displayed very severe noncompliance (Table 3 ).

Table 3. Distribution of Participants by the Features of the SNDR and SNFR Subscales (N = 100)

\begin{tabular}{l|c|c|c|c|c|c|c|c|c|c|}
\hline & \multicolumn{2}{|c|}{ No Nonadherence (0) } & \multicolumn{2}{c|}{ Mild (1) } & \multicolumn{2}{c|}{ Moderate (2) } & \multicolumn{2}{c|}{ Severe (3) } & \multicolumn{2}{c|}{ Very Severe (4) } \\
\cline { 2 - 11 } & $\mathrm{n}$ & $\%$ & $\mathrm{n}$ & $\%$ & $\mathrm{n}$ & $\%$ & $\mathrm{n}$ & $\%$ & $\mathrm{n}$ & $\%$ \\
\hline SNDR $^{*}$ & 31 & 31.0 & 21 & 21.0 & 22 & 22.0 & 7 & 7.0 & 19 & 19.0 \\
SNFR $^{* *}$ & 30 & 30.0 & 31 & 31.0 & 16 & 16.0 & 6 & 6.0 & 17 & 17.0 \\
\hline
\end{tabular}

*Severity of nonadherence to diet restriction (Scored between 0 and 4 points)

**Severity of nonadherence to fluid restriction (Scored between 0 and 4 points)

While the participants' mean and median scores for the frequency of noncompliance to diet restriction (FNDR) were $6.6 \pm 3.2$ and 6.0 respectively, and their mean and median scores for the frequency of noncompliance to fluid restriction (FNFR) were $6.4 \pm 3.8$ and 5.0 respectively, which indicates that the frequency of noncompliance to diet and fluid restriction among the participants was moderate (Table 4).

Table 4. Distribution of the Participants by Their Mean Scores for the FNDR and FNFR Subscales

\begin{tabular}{|c|c|c|c|c|}
\hline & $\mathbf{X} \pm \mathbf{S D}$ & Median & Min & Max \\
\hline $\mathrm{FNDR}^{* * * *}$ & $6.6 \pm 3.2$ & 6.0 & 0 & 14 \\
\hline FNFR $^{* * * *}$ & $6.4 \pm 3.8$ & 5.0 & 0 & 14 \\
\hline
\end{tabular}

${ }^{* * * *}$ Frequency of nonadherence to diet restriction (Assessed over $0-14$ days)

${ }^{* * * *}$ Frequency of nonadherence to fluid restriction (Assessed over 0-14 days)

The variables such as age, gender, marital status, educational status, occupation, general health status, presence and type of comorbid factor, regular medication use and smoking status did not lead to statistically significant differences between the mean scores the participants obtained from the overall PHS ( $>>0.05)$. However, the variables such as the duration of dialysis and daily fluid consumption led to statistically significant differences ( $\mathrm{p}<0.05)$ (Table 5).

The variables such as age, gender, marital status, educational status, occupation, presence and type of comorbid factor and duration of dialysis did not lead to statistically significant differences between the mean scores the participants obtained from the FNDR and FNFR subscales of the DDFQ ( $p>0.05$ ). However, the variables such as the daily fluid consumption, regular use of medication and smoking status led to statistically significant differences between the mean scores obtained from the FNDR and FNFR subscales of the DDFQ $(p<0.05)$. The mean scores the participants obtained from the FNDR subscale of the DDFQ showed a statistically significant difference in terms of their general health status $(\mathrm{p}<0.05)$ (Table 5). 
Tablo 5. Comparison of the Participants' Sociodemographic Characteristics in terms of Their mean PHS score and the Mean Scores for the Subscales of the DDFQ

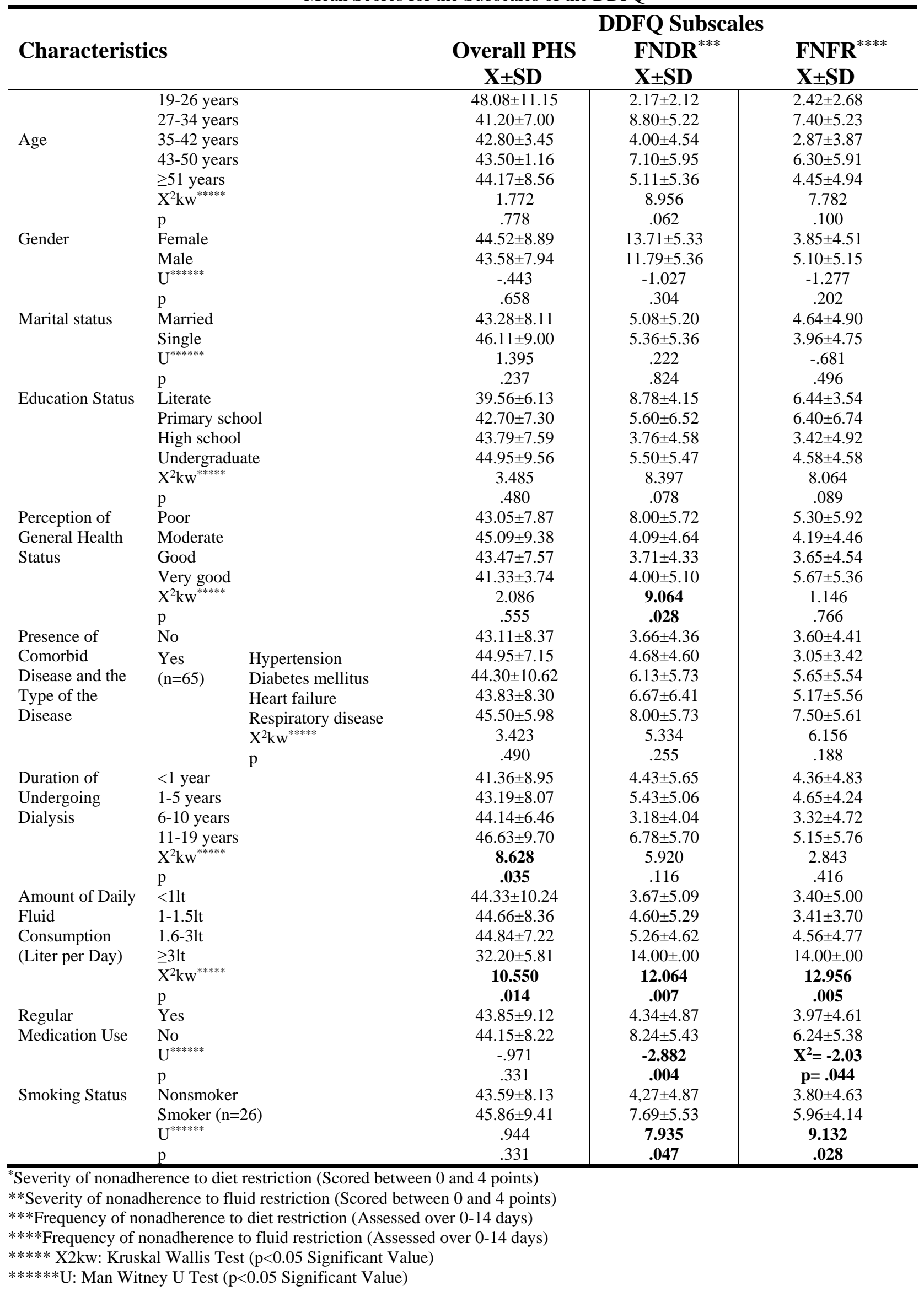


There was a statistically significant weak negative relationship between the overall PHS score and the mean scores of the FNDR, SNDR, FNFR and SNFR subscales of the DDFQ. Although this relationship was weak, it demonstrated that the frequency and severity of noncompliance to diet and fluid restriction decreased as the perception of health increased ( $p$ $<0.05)$ (Table 6).

Table 6. Distribution of the relationship between the mean PHS score and the Mean Scores for the Subscales of the DDFQ

\begin{tabular}{|c|c|c|c|c|c|}
\hline & & FNDR & SNDR & FNFR & SNFR \\
\hline PHS Total & $\begin{array}{l}\mathrm{r} \\
\mathrm{p}\end{array}$ & $\begin{array}{l}-.190^{* * * * * * * *} \\
.040\end{array}$ & $\begin{array}{l}-.198^{* * * * * * * *} \\
.048\end{array}$ & $\begin{array}{l}-.194^{* * * * * * * *} \\
.030\end{array}$ & $\begin{array}{l}-.192^{* * * * * * * *} \\
.042\end{array}$ \\
\hline
\end{tabular}

* Spearman's correlation coefficient, $\mathrm{p}<0.05$

\section{DISCUSSION}

Our search for studies investigating the perception of health in HD dependent individuals and the relationship between the perception of health and diet / fluid restriction demonstrated a gap in the literature. The perception of health, and diet / fluid restriction play an important role in planning and maintaining patients' treatment schedule.

The mean scores the participants obtained from the overall PHS were $44.07 \pm 8.42$ (Table 2). The mean score obtained by the participants from the overall PHS was considered as moderate. Because the perception of health affects health behaviors and health responsibilities and because it is directly related to the process of developing health aiming to acquire and maintain healthy lifestyle behaviors, individuals' having moderate or good level of perception of health is of great importance $[5,24]$.

The variables such as age, gender, marital status, educational status, occupation, general health status, presence and type of comorbid factor, regular medication use and smoking status did not lead to statistically significant differences between the mean scores the participants obtained from the overall PHS ( $>$ > 0.05) (Table 5). However, in the literature, the mean scores for the PHS were determined to be related with age, gender, marital status, educational status, profession, difficulty of the present job, monthly income, general health, smoking, regular use of medication, exercise, family history of kidney disease, presence of comorbid factor, presence of family members dependent on hemodialysis, presenting to emergency services due to illnesses within the last 6 months, receiving nutrition education and the frequency of receiving nutrition education $[6,10,11,12,23,24]$. The review of these studies demonstrated that the study samples consisted of people who had a heart disease and underwent surgery due to heart disease, who had chronic illnesses, who were poor and who were not, who were pregnant and who were not pregnant, and students. The results of the present study were different from those of the studies in the literature, which is thought to be due to the nature of the places and populations where the studies were conducted.

The variables such as the duration of dialysis affected the mean scores obtained from the overall PHS. The overall PHS score increased as the duration of dialysis increased ( $\mathrm{p}<0.05$ ) (Table 4). Ozgur et al. [25] reported that physical functioning and perception of general health deteriorated as the duration of HD increased, and that the sufferer experienced loss of role, and problems in individual relations due to emotional and psychiatric factors. This is thought to be due to the fact that the individuals in the sample were able to well cope with the hemodialysis dependency for many years.

The overall PHS score was lower in the participants whose fluid consumption was high (p <0.05) (Table 4). Beerappa And Chandrababu [26] reported that fluid restriction was the most common stressor in dialysis patients. Since individuals perceive the fluid restriction due to HD treatment as a source of stress, they may not have complied with the fluid restriction and thus they may have developed a perception of poor health. The results of the present study regarding fluid consumption are consistent with those of the studies in the literature.

The analysis of the participants' compliance to diet restriction revealed that $31 \%$ complied with their diet, $21 \%$ displayed mild noncompliance, $22 \%$ displayed moderate noncompliance, $7 \%$ displayed severe noncompliance and $19 \%$ displayed very severe noncompliance. In general, $69 \%$ of the participants displayed noncompliance to diet restriction. The analysis of their compliance to fluid restriction demonstrated that $30 \%$ complied with the fluid restriction, $31 \%$ displayed mild noncompliance, $16 \%$ displayed moderate noncompliance, $6 \%$ displayed severe noncompliance and $17 \%$ displayed very severe noncompliance. In general, $70 \%$ of the participants displayed noncompliance to fluid restriction (Table 3). This present study, it was observed that some factor such as the daily fluid consumption, regular use of medication, smoking status and general health status led to high non-compliance (Tablo 5). Chronic renal failure is a disease that affects sufferers' eating and drinking habits and preferences and may lead to many metabolic, physiological and psychological changes in them [27]. Gunalay et al. [17] conducted a study with individuals who received HD treatment and found that of the participants, $70 \%$ did not comply with the diet restriction and $74 \%$ with the fluid 
restriction. In Beerappa And Chandrababu [26]' s study, of the participants who received HD treatment, 78.3\% did not comply with the diet restriction and $71.7 \%$ with the fluid restriction. In study, Kara [21] found that of the HD treatment recipients, $78.3 \%$ did not comply with the diet restriction and $68.1 \%$ with the fluid restriction. The results of the present study are consistent with those of the studies in the literature.

While the mean score the participants obtained from the frequency of noncompliance to diet restriction (FNDR) was $6.6 \pm 3.2$, the mean score they obtained from the frequency of noncompliance to fluid restriction (FNFR) was $6.4 \pm 3.8$ (Table 4), which suggests that the frequency of noncompliance to diet and fluid restriction among the participants was moderate.

In Efe And Kocaoz [28]'s study, the mean score for the FNDR and FNFR was $6.0 \pm 4.4$ and $6.6 \pm 4.9$ respectively. The results of the present study are consistent with those of the studies in the literature.

The differences between the mean scores the participants obtained from the FNDR and FNFR subscales of the DDFQ in terms of the variables such as age, gender, marital status, educational status, occupation, presence and type of comorbid factor and duration of dialysis were not statistically significant ( $p>0.05$ ). However, the variables such as the regular use of medication, general health status, smoking status and the daily fluid consumption led to statistically significant differences between the mean scores obtained from the FNDR and FNFR subscales of the DDFQ $(p<0.05)$. Regular medication use of the participants affected their mean FNDR and FNFR subscale scores statistically significantly ( $\mathrm{p}<0.05$ ). According to this result, while the mean FNDR subscale score was $8.24 \pm 5.43$ in the participants did not take medication regularly, it was $4.34 \pm 4.87$ in those who took medication regularly. While the mean FNFR subscale score was the highest $(6.24 \pm 5.58)$ among the participants who took medication regularly, it was the lowest $(3.97 \pm 4.61)$ among the participants who did not take medication regularly (Table 6). As is in all chronic diseases, if those who are diagnosed with the End Stage Renal Disease and continue to receive HD therapy are to maintain healthy lifestyle, they have to comply with the drug treatment schedule regularly because this affects their compliance to diet and fluid restrictions $[26,28]$. In studies reported that regular medication use was among the health parameters and played an effective role in the treatment program [29-31].

The mean scores the participants obtained from the FNDR subscale of the DDFQ showed a statistically significant difference in terms of their general health status $(p<0.05)$. The comparison of the perception of health and the mean score obtained from the FNDR subscale of the DDFQ indicated a statistically significant relationship between them ( $p$ $<0.05)$. While the mean FNDR subscale score was the lowest $(3.71 \pm 4.33)$ among the participants who perceived their health status as good, it was the highest $(8.00 \pm 5.72)$ among the participants who perceived their health status as poor. The mean FNFR subscale scores of the participants were not statistically significant in terms of their perception of health (p> 0.05) (Table 5). In the present study, it was determined that noncompliance to diet restriction triggered the perception of poor health, and that compliance to diet restriction led to the perception of good health. In Kara [21] study, it was determined that the rate of noncompliance to HD therapy was 50\% or higher, and that compliance to diet restriction was crucial, if the sufferer was to be successful in the treatment. Estimating the diversity and nature of the difficulties experienced by those with chronic diseases including diabetes due to diet restriction was difficult. Because the concept of diet restriction is open to individuals' own interpretation, and because these people are concerned with this situation at the highest level, these people tend to adopt the idea of noncompliance. Another factor causing these people to display noncompliance behaviors is the fact that various aspects of their environment and living conditions might force them to display such behaviors $[26,32,33]$. In an individual' s compliance to diet restriction, effects of psychosocial factors including his/her beliefs about treatment play a greater role, which suggests that subjective data may help to identify individuals' compliance to diet and may contribute to their recovery from noncompliance if there is any. In this case, individuals' perception of health is important in the assurance of their compliance to diet $[19,34]$.

The participants' smoking status affected the mean scores they obtained from the FNDR and FNFR subscales statistically significantly According to this result, while the mean FNDR subscale score was the highest (7.69 \pm 5.53$)$ among the participants who did not smoke, it was the lowest $(4.27 \pm 4.87)$ among the participants who smoked. While the mean FNFR subscale score was the highest $(5.96 \pm 4.14)$ among the participants who did not smoke, it was the lowest $(3.80 \pm 4.63)$ among the participants who smoked $(\mathrm{p}<0.05)$. The participants' daily fluid consumption affected the mean scores they obtained from the FNDR and FNFR subscales statistically significantly. As the fluid consumption increased, so did the mean FNDR and FNFR scores $(\mathrm{p}<0.05)$ (Table 5). The hemodialysis-dependent individuals are required to pay attention to required conditions by exercising, not drinking alcohol, not smoking, avoiding the nutrients that progress the disease, and complying with fluid restriction. Therefore, it is stated that an individuals' belief indicating that such behaviors will reduce the adverse effects of hemodialysis and slow down the progress of chronic renal failure will raise their awareness of the fact that they should exercise, have a healthy diet, pay attention to daily fluid intake, not consume alcohol and not smoke $[20,27,28]$.

There was a statistically significant weak negative relation between the mean score for the overall PHS and the mean 
scores for the FNDR, SNDR, FNFR and SNFR subscales of the DDFQ (Table 6). Although this relationship was weak, an increase in the perception of health encourages individuals to comply with the diet and fluid restriction, and a decrease discourages them from complying with the diet and fluid restriction. A person's perceiving his/her health as important leads to a decrease in his/her noncompliance to diet and fluid restriction. Finding out what health means to individuals makes it possible to discover whether they adopt the concept of compliance or noncompliance [2,28,34]. In their study, Hicdurmaz And Oz [35] reported that lifestyle changes due to HD therapy did not lead to the perception of threat to their lives thanks to their own perceptions of health and effective coping mechanisms, and that by restructuring their lives, they learned to live with the illness and thus adapted to treatment [35]. Kara stated that determining HD-dependent individuals' perception of health played a role in determining whether they displayed health behaviors of compliance or noncompliance to treatment [21]. In several studies, it has been determined that addressing HD-dependent individuals' compliance to treatment can improve not only the efficacy and quality of the treatment but also these people's health status and perceptions of health $[27,35,36]$. Because HD causes physical and emotional problems and deterioration in perception of health [13]. In addition, patient-related factors, health perceptions, and psychosocial factors have also been associated with no compliance to diet and fluid recommendations among patients with end-stage renal disease in Jordan [32]. This present study, it was observed that some factor such as the daily fluid consumption, regular use of medication, smoking status and general health status led to high non-compliance. In addition, it was observed that some factor such as the duration of dialysis and daily fluid consumption led to be affected the perception of health.

\section{CONCLUSION}

In the present study carried out to determine the effects of perception of health on noncompliance to diet and fluid restriction in hemodialysis-dependent individuals, a significant negative correlation was determined between the mean score for the overall PHS and the mean scores for the FNDR, SNDR, FNFR and SNFR subscales of the DDFQ. As the perception of health increased, so did the compliance to diet and fluid restriction or vice versa. Because the perception of health affects noncompliance to diet and fluid restriction in HD-dependent individuals, health professionals should determine patients' perception of health and should try to improve their perception of health and help them to express how they perceive diet and fluid restriction before and after they start dialysis and provide support to them.

As indicated in several studies, addressing compliance to treatment in HD-dependent individuals may improve not only the efficacy and quality of treatment but also sufferers' well-being and perception of health [18-20]. Lifestyle changes due to hemodialysis HD treatment do not lead to a perception of threat in patients' life thanks to their own perception of health and effective coping mechanisms and facilitate living with the disease and adapting to treatment by restructuring their lives. Perception of general health deteriorates as the duration of HD increased, and that the sufferer experienced loss of role, and problems in individual relations due to emotional and psychiatric factors. Therefore, HD nurses should carefully determine patients' compliance to treatment and lifestyle changes and take necessary steps individually or as a team $[19,20]$. If HD nurses know how a patient perceives and controls his/her health behaviors, they can improve the patient's compliance to HD treatment and lifestyle changes by encouraging his/her right behaviors and improving the wrong ones.

\section{REFERENCES}

[1] Anothaisintawee T, Rattanasiri S, Ingsathit A, Attia J, Thakkinstian A, "Prevalence of chronic kidney disease: A systematic review and meta-analysis", Clinical Nephrology, vol. 71, no. 3, pp. 244-254, 2016. https://doi.org/10.5414/CNP71244

[2] Kacar G, Chronic Kidney Failure and Care. In Z. Durna (Ed.), Cronic Disease and care (p. 392). İstanbul: Nobel Medicine publishing, 2012.

[3] Suleymanlar G, Ates K, Seyahi N, Registry of The Nephrology, Dialysis and Transplantation in Turkey Registry 2018, 2019. Retrieved March 20, 2020, from file://C:/Users/LENOVO/Desktop/REGISTRY_2018.pdf

[4] WKD. World Kidney Day (WKD): Chronic Kidney Disease. 2020. Retrieved March 15, 2020, from https://www.worldkidneyday.org/2020-campaign/2020-wkd-theme/

[5] Doganay S, Ucku SR, "Can poor self-rated health predict coronary heart disease (CHD) and mortality in the elderly people?", Turkish Journal of Geriatrics, vol. 15, no. 4, pp. 396-402, 2012.

[6] Gunay O, İskender G, Ozturk A, Cetinkaya F, Nacar M, "The Effects of Various Factors on Poor Self-Rated Health Among The Older People in Kayseri, Turkey", Turkish Journal of Geriatrics, vol. 8, no. 1, pp. 10-12, 2005.

[7] Wilson IB, Cleary PD, "Linking clinical variables with health-related quality of life", The Journal of the American Medical Association, vol. 273, no. 1, pp. 59-65, 1995.

[8] Inkaya B, Pakyuz SC, "Developing a scale for the perception of health and complaints/symptoms in hemodialysis patients: Turkish version", Journal of Clinical and Analytical Medicine, vol. 8, no. 6, pp. 453-457, 2017. https://doi.org/10.4328/JCAM.5118

[9] Ozturk B, Akin S, Durna Z, Ozdilli K, "Evaluation of the level of knowledge associated with functional 
performance status, quality of life, and fistula care in patients ongoing hemodialysis therapy", Journal of Nephrology Nursing, vol. 1, pp. 24-34, 2013.

[10] Bademli K, Lok N, "Relationshıp Between The Health Perception and Physical Activity of Individuals", Turkish Journal of Sport and Exercise, vol. 20, no. 3, pp.127-129, 2018. https://doi.org/10.15314/tsed.452950

[11] Kadioglu H, Yildiz A, "Validity and reliability of Turkish version of perception of health scale", Turkiye Klinikleri Journal of Medical Sciences, vol. 32, no. 1, pp. 47-53, 2012. https://doi.org/10.5336/medsci.201021761

[12] Plantinga LC, Boulware LE, Coresh J, Stevens LA, Miller ER, Saran R, ... Powe NR, "Patient awareness of chronic kidney disease: Trends and predictors", Archives of Internal Medicine, vol. 168, no. 20, pp. 2268-2275, 2008. https://doi.org/10.1001/archinte.168.20.2268

[13] Tugut N, Bekar M, "Cumhuriyet University Student's Healthy Perception State and the Correlation of Health Promotion Life Style”, Journal of Ataturk University School of Nursing, vol. 11, no. 3, pp. 17-26, 2008.

[14] Beerendrakumar N, Ramamoorthy L, Haridasan S, "Dietary and Fluid Regime Compliance in Chronic Kidney Disease Patients", Journal of Caring Sciences, vol. 7, no. 1, pp. 17-20, 2018. https://doi.org/10.15171/jcs.2018.003

[15] Freedman I, "Cultural specificity in food choice - The case of ethnography in Japan”, Appetite, no. 96, pp. 138146, 2016. doi:10.1016/j.appet.2015.09.006

[16] Swift JA, Tischler V, "Qualitative research in nutrition and dietetics: getting started" Journal of Human Nutrition and Dietetics, vol. 23, no. 6, pp. 559-566, 2010. doi:10.1111/j.1365-277X.2010.01116.x

[17] Gunalay S, Taskiran E, Mergen H, "Evaluation of dietary and fluid restriction noncompliance in patients on hemodialysis", Istanbul Bilim University Florence Nightingale Journal of Medicine, vol. 3, no. 1, pp. 9-14, 2017. https://doi.org/10.5606/fng.btd.2017.003

[18] Rosner, F. Patient noncompliance: Causes and solutions. The Mount Sinai Journal of Medicine, New York, 73, pp. 553-559, 2006.

[19] Murali KM, Mullan J, Roodenrys S, Hassan HC, Lambert K, Lonergan M, "Strategies to improve dietary, fluid, dialysis or medication compliance in patients with end stage kidney disease on dialysis: A systematic review and meta-analysis of randomized intervention trials", PLoS ONE, vol. 14, no. 1, pp. 1-27, 2019. https://doi.org/10.1371/journal.pone.0211479

[20] Elmas A, Saral EE, Tugrul A, Sengul E, Bulbul F, “The Relationship Between The Level Of Nutritional Eduction And Clinical And Laboratory Findings In Hemodialysis Patients”, Medical Journal of Kocaeli, vol. 1, no. 3, pp. 23-26, 2012.

[21] Kara B, A "Validity and Reliability Study of the Noncompliance Questionnaire with Dialysis Diet and Fluid Restrictions", Journal of Ataturk University School of Nursing, vol. 12, no. 3, pp. 20-27, 2010.

[22] Vlaminck H, Maes B, Jacobs A, Reyntjens S, Evers G, “The dialysis diet and fluid noncompliance questionnaire validity testing of a self-report instrument for clinical practice", Journal of Clinical Nursing, vol. 10, pp. 707715, 2001.

[23] Diamond JJ, Becker JA, Arenson CA, Chambers CV, Rosenthal MP, "Development of a scale to measure adults' perceptions of health: Preliminary findings", Journal of Community Psychology, vol. 35, no. 5, pp. 557561, 2007. https://doi.org/doi:10.1002/jcop.20164

[24] Aciksoz S, Uzun S, Arslan F, "Relationship between perceptions of health status and health promotion behaviors in nursing students", Gulhane Medical Journal, vol. 55, pp.181-187, 2013. https://doi.org/10.5455/gulhane.15228

[25] Ozgur B, Kursat S, Aydemir O. "Evauuation of Quality of Life With the Leveus of Depression and Anxiety in Hemodialysis Patients", Official Journal of the Turkish Society of Nephrology, vol. 12, no. 2, pp. 113-116, 2003.

[26] Beerappa H, Chandrababu R, "Compliance to dietary and fluid restrictions among patients undergoing hemodialysis: An observational study", Clinical Epidemiology and Global Health, vol. 7, no. 1, pp. 127-130, 2019. https://doi.org/10.1016/J.CEGH.2018.05.003

[27] Opiyo RO, Nyasulu PS, Olenja J, Zunza M, Nguyen KA, Bukania Z, ... Were AO, "Factors associated with compliance to dietary prescription among adult patients with chronic kidney disease on hemodialysis in national referral hospitals in Kenya: a mixed-methods survey", Renal Replacement Therapy, vol. 5, no. 1, pp. 1-14, 2019. https://doi.org/10.1186/s41100-019-0237-4

[28]Efe D, Kocaoz S, "Compliance to diet and fluid restriction of individuals on hemodialysis treatment and affecting factors in Turkey", Japan Journal of Nursing Science, vol. 12, no. 2, pp. 113-123, 2015. https://doi.org/doi:10.1111/jjns.12055

[29] Walt G, “WHO's World Health Report 2003”. BMJ, vol. 328, no. 7430, p. $6, \quad 2004$. https://doi.org/10.1136/bmj.328.7430.6

[30] Ho PM, Bryson CL, Rumsfeld JS, "Medication Compliance”, Circulation, vol. 119, no. 23, pp. 3028-3035, 2009. https://doi.org/10.1161/CIRCULATIONAHA.108.768986

[31] Kvarnström K, Airaksinen M, Liira H, "Barriers and facilitators to medication compliance: a qualitative study 
with general practitioners”, BMJ Open, vol. 8, no. 1, pp. e015332, 2018. https://doi.org/10.1136/bmjopen-2016015332

[32] Khalil AA, Darawad MA, Gamal E, Hamdan-Mansour AM, Abed MA, "Predictors of dietary and fluid noncompliance in Jordanian patients with end-stage renal disease receiving haemodialysis: a cross-sectional study", Journal of Clinical Nursing, vol. 22, no. 1-2, pp. 127-136, 2013. https://doi.org/doi:10.1111/j.13652702.2012.04117.x

[33] Rita M, Boothby K, Salmon P, "The Grounding of the Construct of Self-Efficacy in Type 2 Diabetic Patients ' Own Thinking”, Turkiye Klinikleri Journal of Endocrinology, vol. 5, no, 2, 2010.

[34] Krespi Boothby M, Salmon P, "Self-Efficacy and Hemodialysis Treatment: A Qualitative and Quantitative Approach". Turkish Journal of Psychiatry, vol. 24, no. 2, pp. 84-93, 2013.

[35] Hicdurmaz D, Oz F, "Coping Styles of Patients Taking Hemodialysis and Continuous Ambulatory Peritoneal Dialysis Treatment”, Journal of Hacettepe University Faculty of Nursing, vol. 16, no. 3, pp. 1-16, 2009.

[36] Naalweh KS, Barakat MA, Sweileh MW, Al-Jabi SW, Sweileh WM, Zyoud SH, "Treatment compliance and perception in patients on maintenance hemodialysis: A cross - Sectional study from Palestine", BMC Nephrology, vol. 18, no. 1, pp. 1-9, 2017. https://doi.org/10.1186/s12882-017-0598-2 